University of Louisville

ThinkIR: The University of Louisville's Institutional Repository

Electronic Theses and Dissertations

1936

\title{
A study of furoyl chloride.
}

Luella Shehan

University of Louisville

Follow this and additional works at: https://ir.library.louisville.edu/etd

Part of the Chemistry Commons

\section{Recommended Citation}

Shehan, Luella, "A study of furoyl chloride." (1936). Electronic Theses and Dissertations. Paper 1894. https://doi.org/10.18297/etd/1894

This Master's Thesis is brought to you for free and open access by ThinkIR: The University of Louisville's Institutional Repository. It has been accepted for inclusion in Electronic Theses and Dissertations by an authorized administrator of ThinkIR: The University of Louisville's Institutional Repository. This title appears here courtesy of the author, who has retained all other copyrights. For more information, please contact thinkir@louisville.edu. 
UNIVERSITY OF LOIISVILIE

A STUDY OF FUROYI C LORIDE

\author{
A Dissertation \\ Submitted to the Faculty of the \\ Graduate School of the University of Louisville \\ In Partial Fulfillment of the \\ Requirements for the Degree \\ of Master of Science
}

- Department of Chemistry

By

Iuella Shehan

1936 
TABLE OF CONTENTS

Page No.

I. Introduction

A.The Furans.....................

B. Huroyl Chloride..................

II. Buroyl Chloride:Preparation

A.Theoretical...................

B.objective.......................

C.Experimental..................6

D.Equations........................

E.Conclusions.....................

III. Furoyl Chloride:Reaction with Tertaric Acid

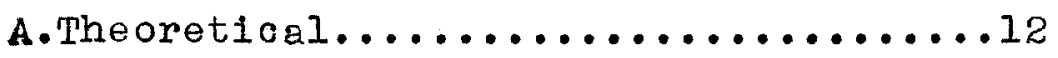

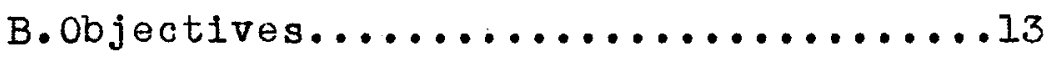

C.Experimentel...................14

D. Equations....................20

E.Conclusions...................2l

IV.Furoyl Chloride:Reaction with Ethylene Glycol

A.Theoreticel..................22

B. Objectives...................23

C.Experimental..................24

D.Equations....................2E

E.Conclusions..................29 
Page No.

V.Furoyl ChIoride:Reaction with Glycerol

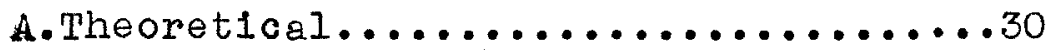

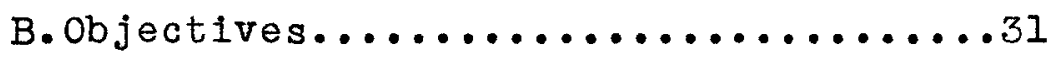

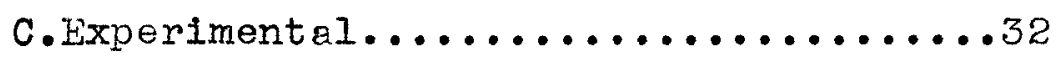

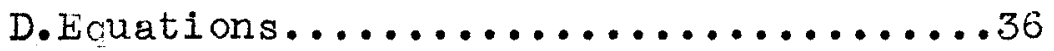

E.Conclusions...........................

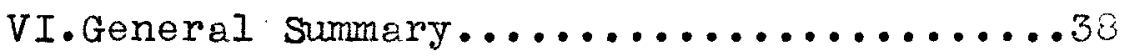

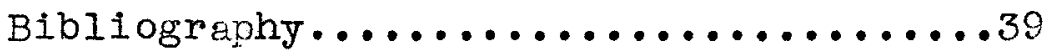


I. Introduction 


\section{A.The Furans}

In the field of chemistry,particularly that of organic chemistry, the last decade has witnessed the rise to recognition and importance of many comoounds, heretofore considered only as laboratory curiosities.For over 100 years furfural has been known but little used.It was first orepared by Dobereiner(I) in 1630 while he was preparing formic acid from sugar by the action of manganese dioxide and sulfuric acid. There followed a half century of indifference and lack of interest in the subject,after which rather extensive investigations were undertaken on the preparation and properties of furfural.Eventually it was recognized that pentoses and pentosans were the substances ordinarily yielding furfural. With this fact in mind, numerous methods for the preparation of furfural have been devised, the raw materials including oat hulls, tobacco stems, corn cobs, wood waste, sunflower seed and straw. Furfural production has increased from a few barrels per year to millions of pounds oer year.

Furfural is a pale yellow or water white liquid which boils at $158^{\circ}-168^{\circ} \mathrm{C}$.It has a flesh point of $55^{\circ}-57^{\circ} \mathrm{C}$. and its specific gravity is 1.159-1.161 (2). Furfural is an aldehyaje the reactions of which are similar to those of formaldehyde and benzaldehyde (3). Yet the furan ring 
structure is responsible for many curious properties found in neither of these two typical aldehydes.As can be expected from a study of its structure,furfural serves as the source compound for a group of compounds not hitherto available. Many of these derivatives have been prepared and can now be had as commercial need for them arises.It is to furfural and this series of compounds that we refer as "The Thrans". They include furfuryl alcohol, ethyl furoate, furoyl chloride, hydrofuramide, tetrahydrofurfuryl alcohol and others.The furans as a group have several characteristic properties. They are, in general, high boiling compounds which are fairly stable despite their tendency to arrken on standing. They are, however, highly semative to acidic reagents due to the effect which these substances seem to have on the furan ring (3). Due to their distinctive properties these furfural derivatives are finding extensive apolication in widely divergent fields of industry. They are being used as solvents, as accelerators in certain kinds of rubber, as constituents of resins,perfumes, fungicides, and dyestuffs, and in numerous other capacities in industrial production. 


\section{B. Furoyl Chloride}

The member of this series of furfural derivatives or furans with which this paper is particularly concerned is furoyl chloride, commonly referred to in the earlier literature as pyromucyl chloride.Furoyl chloride was first prepared by the action of phosphorous pentachloride on furoic acid (4). Later methods of preparation include: a modification of the original method by Frankland and Aston (5), who devised a special method of procedure; the treatment of furoic acid with thionyl chloride on a water batin (6); the use of benzene as a solvent in the last mentioned process (7); and a slight modification of this process, which is the one most in use at present (c). The yields in this process are ebout $89 \%$

Furgyl chloride is a colorless, strongly refracting liquid which boils at $170^{\circ} \mathrm{C}$. It is more stable than benzoyl chloride, being unaffected by cold water and only slightly attacked by hot water. It is a vigorous lachrymator, the vapor being quite irritable to the eyes. With ammonia,furoyl chloride reatts to give furamide. With hydrogen cyanide, in the presence of pyridine, furoyl chloride forms furoyl cyanide, which on hydrolysis with hydrochloric acid gives furoyl formic acid (3). Due to its stability and mutiplicity of reactions furoyl chloride is one of the most useful of the furans from a synthetic point of view (8). 
II. Furoyl Chloride:Preparation 


\section{A. Theoretical}

As was mentioned earlier in this paper, furfural resembles benzaldehyde in some of its reactions (3). This is particularly true where the aldehyde group alone is involved.In 1832 Liebig and Wohler(9) obtained the first acid chloride when they treated benzaldehyde with chlorine to form benzoyl chloride. Therefore, on the basis of the analogy between the reactions of benzaldehyde and furfural, the preparation of furoyl chloride from the chlorination of furfural can be assumed as a nossibility.Before such a reaction could be undertaken there was one disturbing factor which had to be taken into consideration. In view of the high sensitivity of the furans to hyarochloric acid and the fact that this acid would be produced in the suggested reaction, some provision had to be made for the removel of this acid as soon as it was formed. In 1908, however, as a result of experiments(10) pyridine bases were suggested as halogen carriers in reactions involving halogen substitution.Later Darzens(11) used pyriaine to unite witn the hydrochloric acid formed when chlorides are prepared from alcohols. Kirner (12) usea the same means of hydrochloric acid removal in the conversion of furfuryl alcohol into furfuryl chloride. Due to the success with which these men used pyridine in dealing with the 
furans in the presence of hydrochloric acid,it was thought edvisable in this study to use pyridine.

$$
\text { B. Objective }
$$

The objective of this study is to show the similarity between the activity of furfural and that of benzaldehyde with chlorine, by the preparation of furoyl chloride. 


\section{C.Experimental}

Experiment No.\#FPreparation of Pyridine Dichloride

This reaction was carried out in a $250 \mathrm{cc}$. round bottom flask(three neck). To one opening was a delivery tube leading from a chlorine generator containing 0.5 mol manganese dioxide and 2.0 mols of hydrochloric acid. The center opening of the flask was fitted with a nercury sealed, motor ariven stirrer.From the remaining opening was an outlet tube leading through a trap into a bottle containing a ailute solution of sodiom hydroxide.0.2 mol of pyridine and 25 ca.of anhydrous ether were placed in the flask and stirred vigorously, the entire flask being immersed in an ice bath. When the temperature had fallen to about $6^{\circ}$ tine cillorine was slowly bubblea into the pyridine solution, which was stirrea constantly. When about one-half of the chlorine had been introduced small white crystals began to form on the sides of the flask. By the time all of the chloeine had been introduced a white crystalline mass remained. The crystals were very unstable,however, and turned yellow and brown as soon as they came into contact with the air. When these crytals were isolated ana exanined they were found to manifest all of the properties ascribed to pyridine dichloride, $\int_{C 1 \mathrm{Cl}}$, in the literature(13). 
Experiment No.\#2-Preparation of Fyridine Hydrochloride A mixture of $0.2 \mathrm{~mol}$ of uridine and $25 \mathrm{cc}$. of $\mathrm{en}-$ hydrous ether was treated in ex ctly the same fashion as that described on the preceding experiment,with the exception that hydrogen chloride wes introduced instead of chlorine. The hydrogen chloride was generatea from a flask containing sodium chloride and concentrated sulfuric acia. The product winich resulted onsisted of white hygroscopic crystils with all of the properties ascribed to pyridine hyarochloride, (14)(15).

Experiment No.\#3-Attempted Preparation of Furoyl Chloride The furfural used in this and subsequent experiments was purified by distillation (3). The technical furfural was distilled under reduced pressure $(30 \mathrm{~mm}$.), the fraction containing the last $65 \%$ of the distillate being collected and stored in amber colored bottles.A mixture of $25 \mathrm{cc}$. of anhydrous ether and $0.2 \mathrm{~mol}$ of purified furfural was olaced in a $500 \mathrm{cc}$. round bottom flask, $0.2 \mathrm{~mol}$ of pyridine was added and the flask immersed in an ice bath. The openings of the flask were fitted as in the two preceding experiments. The solution was stirred until the temocrature reached $6^{\circ} \mathrm{C}$.Chlorine was slowy bubblea into the solution over a period of two hours. When about one-half of the chlorine had been introduced, wite crystals began to form around the edge of the solution. As the reaction proceeded, however, they turned yellow. At the end of two hours the ether 
solution was extracted anā distilleà under reciucea pressure (30 mm.), the major portion of the distillate coming over at $48^{\circ} \mathrm{C}$. Treatment of the aistillate with concentrated ammonium hydroxide yielded a white precipitate which melted at $117^{\circ}-121^{\circ}$ Co, hydrofuramide. Hydrofuramide is the ammonia derivative of furfural, therefore the distillate consisted of unchanged furfural. An exmination of the crystels which remained in the flask revealed all of the properties ascribed to pyridine dichloride (13).

Experiment ivo.\#\# 4-Attemptea Preparation of Furoyl Chloride A mixture of $0.2 \mathrm{~mol}$ of furfural and $25 \mathrm{cc}$. of ether was treated in exactly the same fashion as that outlined in the preceaing experiment, with the exception that the reaction was carried out at room temperature. The white crystals formed as before, but decomposed mote readily into a brown waxy mass wilich eventually turned into a brown liquid. Ihe ethereal solution after aistillation again yielded en ammonia derivative which melted at $117^{\circ}-121^{\circ} \mathrm{C}$, hydrofuramide.As before, this derivative indicated the presence of unchenged furfural.

Experiment No.\# 5-Attempted preparation of Furoyl Chloride As before, a mixture of $.2 \mathrm{~mol}$ of furfural and $25 \mathrm{cc}$. of ether was chlorinated,but in the absence of pyridine $A$ yellow oily liquid was produced which turned reddish brown as the reaction proseded.Two layers formed in the solution 
The ether layer formed an armonia derivative melting at $117^{\circ}-121^{\circ} \mathrm{C}$. The other layer which was very acid was cooled to $5^{\circ} \mathrm{C}$. No crystals appeared. The properties of furoyl chloride were revelied in none of the products formed. The ammonia derivative was that of furfural. Furthermore, no lachrymatory effect,a characteristic of furoyl chloride,was noticed.The The furfural was aporently unchenged. The absence of crystals in this reaction in which pyridine was absent might be taiken as further proof of the fact that the crystals in the two preceding reactions were pyridine compounds. Experiment No.\# 6-Reaction of Aldehydes and Acid Chlorides A mixture of $0.2 \mathrm{~mol}$ of furfural and furoyl chloride was laced in a tightly stoppered flask and allowed to stand in contat with one another for eight hours. Apparently no reaction took place for there was no change in the appearance of the mixture.This experiment was performed to determine the properties of a solid adaition product formed from the reaction between an alcehyde and acyl halide, as is true in the case of benzaldehyde and benzoyl chloride(17). Apparently furoyl chloride and furfural do not react in this manner. 


\section{Equetions}

Predieted reation:

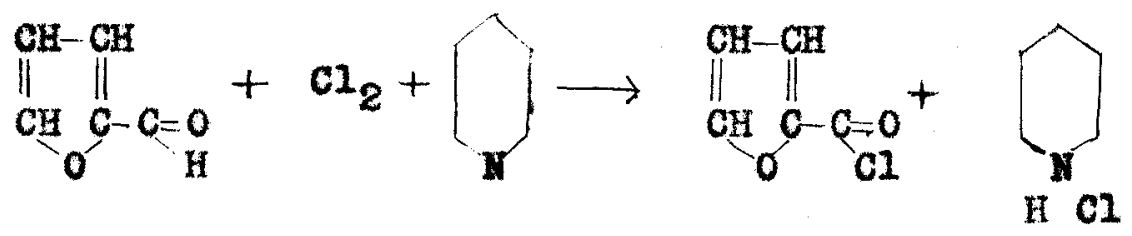

Aotual reaction:

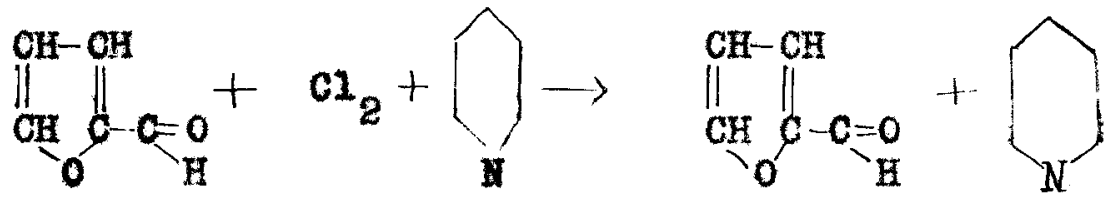

$$
\begin{aligned}
& \mathrm{Cl} \mathrm{Cl}
\end{aligned}
$$




\section{E. Conclusions}

1. The precipitate which fowed in every reaction in which pyridihe was present did not possess the proterties ascribed to pyriaine-HCl salt(14)(15). Neither can it be ettributed to the formation of a solid addition product formed from the reaction between an aldehyde and an acyl halide in the halogenation of an aldehyde (17), for furfural and furoyl chloride apparently do not react in this manner.

2. The properties of the precipitate which formed indicated that it was the dichloride of oyridine. From this it can be inferred that at zeast a major portion of the chlorine was used by the pyridine rather than by the furfural.

3. The findings of these experiments indicate that the investigator was unable to accomplish the recetion between chlorine and furfural to produce furoyl chloride. Likewise the attempt to use pyridine as a halogen carrier was unsuccessful. 
II. Furoyl Chloride:Reaction with Tartaric Acid 
A. Theoretical

The general properties of furoyl chloride have been shown to be quite similar to those of benzoyl chloride (3). As a result of experimentation (21) general claim has been made to the preparation of esters of hydroxy acids having more than one carboxyl group in which a hydrogen of the hydroxyl group is replaced by a benzoyl group. Thus monobenzoyl butyl tartrate has been prepared as a result of of the reaction between dibutyl tartrate and benzoyl chloride. Furthermore, in 1901 Frankland and Ashton (5) demonstrated the action of furoyl chloride on hydroxyl groups by the preparation of diethylpyromcyltartrate,

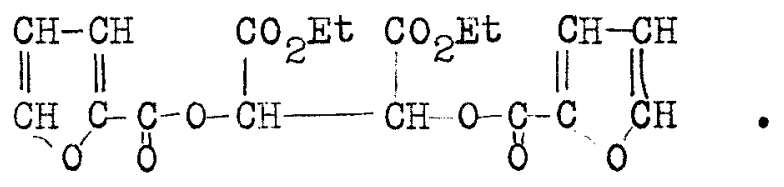

That furoyl chloride might be assumed to react in a manner analogous to that of benzoyl chloride is demonstrated by the fact that Baumann (22) has shown that furoyl chloride can relace benzoyl chloride in the scotten-Baumann reaction, in which componnds are formed with the hyaroxyl groups. 


\section{B.Objectives}

The objectives of this study are:

1. To give further proof of the similarity between the reactions of benzoyl chloride and those of furoyl chloride;

2.To demonstrate the esterification of the hydroxyl groups of tartaric acid by furoyl chloride;

3.To isolate and identify the reaction product of the above reaction. 


\section{C.Experimental}

Experiment No.\# I-Preparation of Furoyl Chloride

The general method of preparation used was that

outlined by Hartman and Dickey (8). The reaction was carried out in a three neck,500 cc. round bottom flask, fitted with a thermometer, a separatory funnel and an inverted Liebig condenser arranged in such a way as to remove the hydrogen chloride and sulfur dioxide formed during the reaction. A mixture of $0.2 \mathrm{~mol}$ of furoic ecid and $35 \mathrm{cc}$. of dry benzene was placed in the flask and heated to gentle refluxing on a water bath. From the separatory funnel $0.3 \mathrm{~mol}$ of thionyl chloride was added gradually, about $3 \mathrm{cc}$. at a time.The entire mixture was heated, gentle refluxing being continued for about 12 hours. After being cooled the rection mixture was filtered into a Claissen flask and the benzene and excess thionyl chloride removed by distillation. The furoyl chloride was distillea unàer reduced pressure (20 ram.), the major portion distilling over at $76^{\circ}-80^{\circ} \mathrm{C}$. The yield was approximately $85 \%$.

Experiment No.\# 2-Preparation and Isolation of the Ester A mixture consisting of $0.2 \mathrm{~mol}$ of furoyl chloride and 0.1 mol of tartaric acid m.p. $170^{\circ} \mathrm{c}$.) was placed in a $250 \mathrm{cc}$. round bottom flask and heated to gentle re- 
fluxing for 5-6 hours. If heated above $120^{\circ} \mathrm{C}$, a black tarry mass separated, so the temperature was maintained below $100^{\circ} \mathrm{C}$. by heating on a water bath. After the mixture was cooled it was filtered. The filtrate was shaken vigorously with a $10 \%$ solution of sodium carbonate. Following some preliminary effervescence, due to the presence of some unchanged furoyl chloride, a light brown emulsion formed and settled to the bottom of the flask. The mixture was immersed in an ice bath and in about ten minutes crystals began to appear.These crystals were filtered off,recrystallized from anhydrous ether, and allowed to dry on a porous plate.The yield was very small, approximately $25 \%$.

Experiment No.\#3-Identification of the Ester

A study of the product of the above reaction revealed the following:

a. Appearance

The product was a white crystalline substance, the crystals being fluffy and needle-shaped. On ignition of the compound no residue remeined. b. Solubility

The reaction product was soluble in ether and alconol, but insoluble in water. c.Physical constants

(1) Melting point The compound melted at $68^{\circ}-70^{\circ} \mathrm{C}$. (uncorrected). 
(2) Molecular weight

The molecular weight was aetermined by mith's and Young's modification of the Rast method for the determination of molecular weights (23).A capillary tube about $2 \mathrm{~mm}$. in diameter and $10 \mathrm{~cm}$. in length was made by arawing out a piece of heavy walled glass tubing. This was weighed accurately on an analytical balance and a known amount of the comound under examination was placed in the tube. A known weight of camphor, approximately ten times the amount of the sample was tightly packed into the tube. The tube was then carefully sealed in a flame, following which the total weight of the tube, samole, and camphor was determined. The contents of the tube were thoroughly mixed by repeated melting and shaking. When mixing was complete the tube was carefully wired to a thermometer and immersed in an oil bath,as in the determination of a melting point.As the temperature was gradually rased the contents of the tube were observed very closely, preferably with an electric light in the background. The temperature at which the last small crystal disappeared was recorded. The bath was slowly cooled and the temperature at which the first small crystal reappered was recorded.There was a $l a g$ of two or three de- 
grees between these readings.The readings were taken three times each for the ascending and descending temperatures.The values obtained were substituted in the following equation which is besed on the principle that the compound under examination acts es an impurity in lowering the melting point of camphor:

$$
\text { Mol.Wt. }=\frac{39.7 \times 1000 \times \text { wt.sample }}{D \text { t } \times \text { wt.camphor }}
$$

The following were the values obtained:

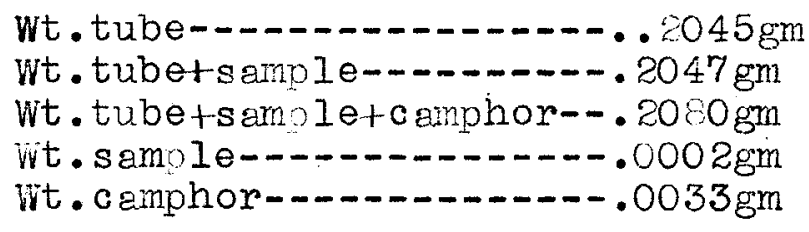

Temperatures

$\begin{array}{ll}171.5^{\circ} & 168.0^{\circ} \\ 170.0^{\circ} & 167.5^{\circ} \\ 170.5^{\circ} & 160.0^{\circ}\end{array}$

Average temp. $=169.25^{\circ}$

Mol.Wt. $=\frac{39.7 \times 1000 \times .0002}{(176.4-169.25) .0003}$

Mol. Wt. $=336.5$

(Calcula ted Mol. Wt. $=338$

$\%$ error $=.44 \%$

(3) Sap onification Equivalent (24)

2.0 gm of finely cut sodium were placed

in $50 \mathrm{cc}$. of absolute alcohol and $10 \mathrm{cc}$. of

water were added. When all of the sodium had

dissolved the alkalinity of this solution 
was determined by titration with standard acid.An accurately weighed amount of the solid sample and $40 \mathrm{cc}$. of the alkali were placed in a round bottom flask and the mixture was heated for 30 minutes to gentle refluxing. After the solution had cooled a $10 \mathrm{cc}$. portion was withdrawn and titratec against standard acid.

$10 \mathrm{cc.alkali}=35.3 \mathrm{cc} . \% 1123 \mathrm{~N} \mathrm{HCl}$

$.3964 \mathrm{~N}=$ ivomality of alkali

cc.N acid required for $40 \mathrm{cc}$ alkali= $40 \times .3964=15.856$ cc. $\mathbb{N}$ acid reouired for excess alkali= cc.N alkali used by samole

$$
57.1 \times .1123=\frac{6.4123}{9.4437}
$$$$
\begin{aligned}
& \text { S.E. } \frac{\text { wt.sampleX } 1000}{\text { c.N } \frac{\text { alkali used }}{1 \mathrm{ka}}} \\
& \text { S.E. } \frac{.2795 \times 1000}{9.4437} \\
& \text { S.E. }=295.9
\end{aligned}
$$$$
\text { (CrIulated S.E. }=299.0
$$$$
\% \text { error }=1.04 \%)
$$

\section{d. Derivatives}

The remainder of the alkaline scoonification product was ecidified with dilute sulfuric acid and shaken with $10 \mathrm{cc}$. of snhydrous ether. lhe ether layer was evaporated leaving white crystals which when examined could be indentified as furoic acid (m.p. $128^{\circ} \mathrm{c}$.) The water soluble 
layer was evaporated leaving white crystals which when treated with a b-naphthol- $\mathrm{H}_{2} \mathrm{SO}_{4}$ solution produced a blue green color changing to an intense green, a color test for tartaric $\operatorname{acid}(2 \theta)$. 


\section{Equations}

The reactions involved in the above described experiments may be represented by the following ecuetions:

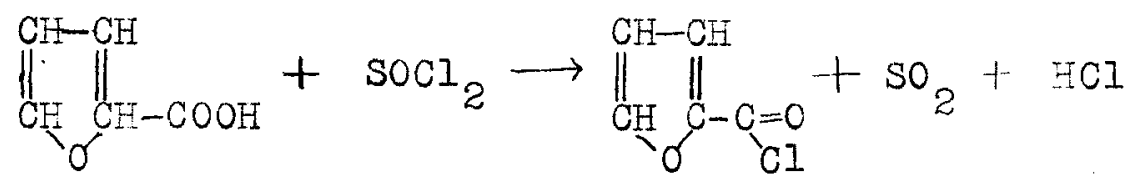<smiles>O=C(O)c1ccco1</smiles>

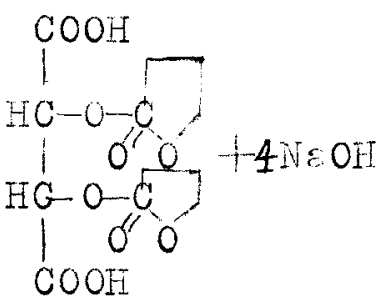<smiles>CCC(C(=O)O)[C@@H](O)[C@@H](O)C(=O)O</smiles>

$\left\|_{\mathrm{C}_{2}}^{\mathrm{CH}-\mathrm{CH}}\right\|_{\mathrm{C}-\mathrm{COONa}}^{\mathrm{CH}}+2 \mathrm{H}_{2} \mathrm{SO}_{4} \rightarrow\left\|_{\mathrm{CH}}^{\mathrm{CH}-\mathrm{CH}}\right\|_{\mathrm{C}}^{\mathrm{COOH}}+\mathrm{Na}_{2} \mathrm{SO}$

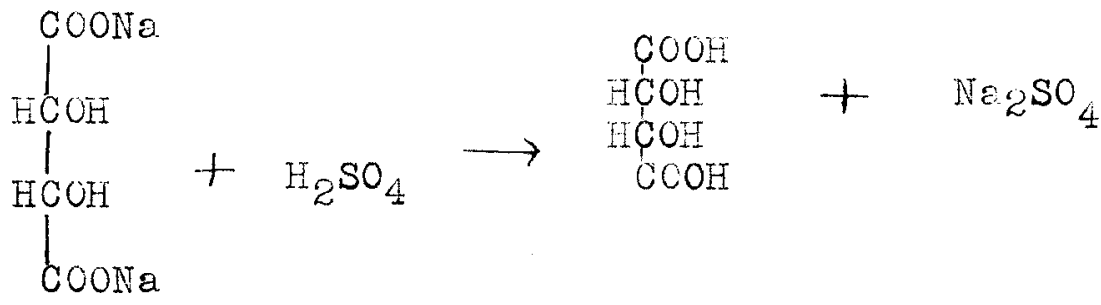




\section{E. Conclusions}

The findings of these experiments indicate that:

1. Furoyl chloride reacts with the hyaroxyl groups of tartaric acid in 2 mener analogous to thet of benzoyl chloride.

2. When furoyl chloride reacts with the hydroxyl Eroups of tartaric ecid an ester is formed. 3. The behaviour of the compound formed incicctes it to be difuroyltartrate, which has not been previously prepared.

4. The physical and cherical properties were determined as fer as possible. 
IV.Furoyl Chloride:Reaction with GIycol 


\section{A. Theoretical}

As was stated above (p.I2), the activity of furoyl chloride is quite similar to that of benzoyl chloride. In 1888 Beumann (25) demonstreted for the first time that polyhydric alcohols cah be isolated in an insoluble form as the benzoyl ester.A dilute solution of the alcohol was shaken with benzoyl chloride and soaium hyaroxide for a few minutes and the ester wis produced. In the following year skraup (26) demonstreted thet these esters of polyhydric elcohols are elweys resinous compounàs which crystellize only on repeated purification with alcohol. They are difficultly soluble in water.ether, and cold alcohol,but soluble in hot alcohol end benzene. Later Diez (27) devised a simple method for the detection of small amounts of glycerine by the use of the above metiod, and at present benzoyl esters are emong the most commonly preparea derivetives of polyhyaric elcohols (28). The benzoyl esters of glycol,glycerine, erythritol, and mennitol heve been preparea end their physical constants determined. The glycol ester, ethylene dibenzoste,melts at $70^{\circ}-71^{\circ} \mathrm{C} \cdot(20)$ 


\section{B. Objectives}

The objectives of this stuay are:

1. To demonstrate the similarity between the activities of benzoyl chloride and furoyl chloride;

2. To demonstrate the reation of furoyl chloride on the hydroxyl groups of a polyhydric alcohol, ethylene $81 \mathrm{ycol}$;

3.To isolate and identify the product formed by the action of furoyl chloride on ethylene glycol. 


\section{C.Experimentel}

Experiment No.\# 1-Preparation of Furoyl Chloride

The furoyl chloride used in this experiment was prepared eccording to the method outlined above(III, C, 10).

Experiment No.\# 2-Preparation and Isolation of the Ester

A mixture consisting of $4 \mathrm{cc}$. of glycol(from which 8lI the weter hed been removed), $10 \mathrm{cc}$. of furoyl chloride, and $50 \mathrm{cc}$. of $10 \%$ sodium hydroxide was pleced in en eight inch test tube. The tube wes stopperec tightly and sheken vijorously under colo weter for several minutes until a white solid separated out.l5 $\mathrm{cc}$. of cold water were sdaed and the shaking continued for 2 min tes. The precipitate wes filtered end weshed with cold water followed by dilute acetic acid. The precipitate was uissolved and recrystelized from hot dilute alcohol. The crystals were dried on a porous plate. The yield was epproximet ely $50 \%$.

Experiment No.\# 3-Identificetion of the lister An examination of the ester revecled the following: a. Appeerene

The product was a white crystalline compound, the crystals being very fine end needle-sheped. On ignition no residue remined, showing that the compound consisted essentially of carbon,hydrogen, 
or oxygen and contrinea no metalic elements.

b. Solubility

The compoundwas soluble in ether and hot alcohol,

but insoluble in weter end cold alcohol.

c.Physical constants

(1) Melting point

The compound relted at $110^{\circ} \mathrm{C}$. (uncorrected).

(2) Molecular weight

The moleculer weight was determined by the method previously outlined(this thesis III, C, 16).

The values obtained were:

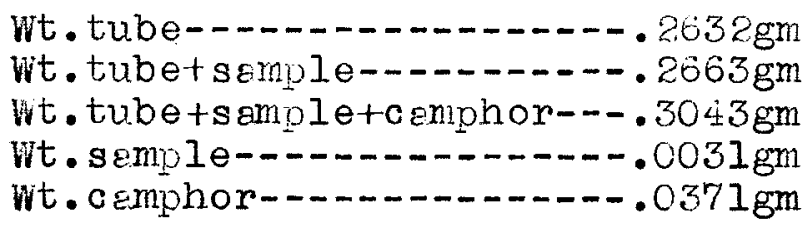

Temperatures

$$
\begin{aligned}
& \begin{array}{cc}
164.5^{\circ} & 162.5^{\circ} \\
105.0^{\circ} & 162.0^{\circ} \\
164.0^{\circ} & 161.5^{\circ}
\end{array} \\
& \text { Average temp. }=163.0^{\circ} \\
& \text { Mol.Wt }=\frac{39.7 \times 1000 \times .0031}{(176.4-163.0) .0371} \\
& \text { Mol.Wt. }=\begin{array}{cc}
248.1 & (\text { celculated } \mathrm{mol} . \mathrm{Wt} .=250 \\
\% \text { error }=.76 \%)
\end{array}
\end{aligned}
$$

(3) Saponificetion Eouivalent

The procedure followed wis that previously outlined (this thesis III,C,I7). 
The following values were obteined:

$10 \mathrm{cc.elkali}=21.3 \mathrm{cc} / . .08937 \mathrm{~N} \mathrm{HCl}$

$.19088 \mathrm{~N}=$ Nomelity of alkali

co. I acia recuired for 40 co.elkali=

$40 \times .19088=7.6076$

co.N acid required for excess alkall=

ca.N Elkall used by sanple

$73.8 \times .08937 \div 5955$

$$
\begin{aligned}
& \text { S.E. }=\frac{.2268 \times 1000}{1.0121} \\
& \text { S.E. }=284.8
\end{aligned}
$$

(Calculeted S.E. $=2,24$

$\%$ error $=.31 \%$

\section{d. Derivatives}

From the seponificetion mixture $5 \mathrm{cc}$. were distillea. The aistillate was evaporated to aryness and the residue was extrected with a mixture of alcohol and etwer. The solvent was evaporcted leaving a syrup. One drop of this syrup was mixea with $0.5 \mathrm{gm}$ of potassium acid silphet e and the mixture wes placed in a test tube fitted with a delivery tube leading into a flesk of distillea water. The sulphate mixture was ignited until frothing ceased and the mess completely liquefied.A 2 cc. portion of this mixture was witharawn and treated with $5 \mathrm{cc}$. of fuchsine aldehyde reagent.A lavendar-pink coloration resulted showing the presence of an aldehyde, 
acetaldehyde, produced by the decomposition of ethylene glycol.By this exeminetion of the seponification products the presence of the glycol grouping in the compound formed was demonstreted. The remeinder of the alkaline saponification product was acidified with dilute sulfuric acid cnd shaken with ether. The ether leyer was eveporeted leaving white crystals which were furoic acid (m.p. $\left.128^{\circ} \mathrm{C}.\right)$. 


\section{Eauations}

The reactions involved in the above aescribed experiments may be revresented by the following equations:

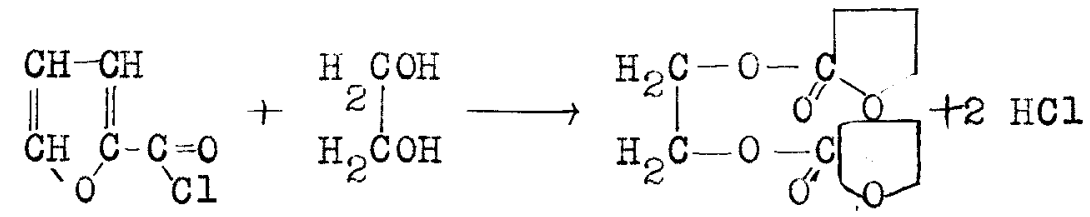

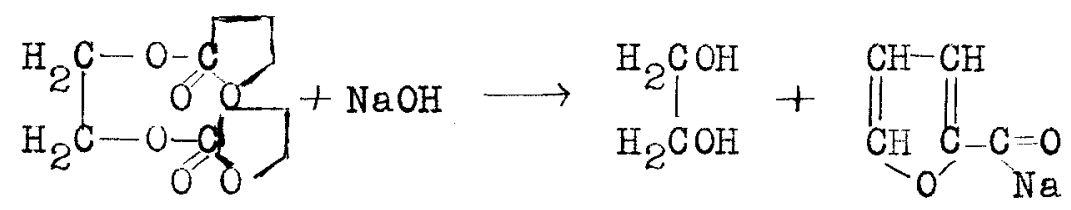

$\mathrm{H}_{2} \mathrm{COH} \quad-\mathrm{H}_{2} \mathrm{O} \longrightarrow \mathrm{CH}_{3} \mathrm{CHO} \quad$ Fuchsine aldehyae, pink

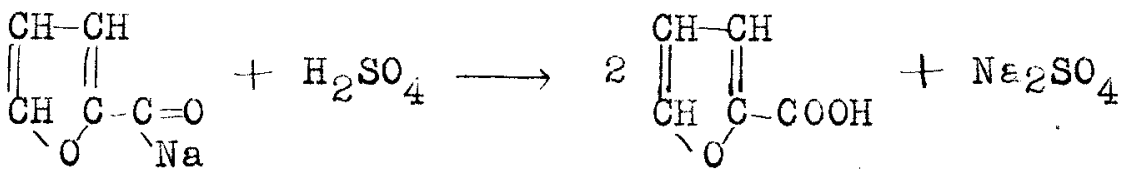


E. Conclusions

The findings of these experiments serve as a basis for the following conclusions:

1. Furoyl do loride rects with both of the hydroxyl groups of ethylene glycol in a menner enclogous to that of benzoyl chloride.

2. Furoyl chloride reacts with ethylene glycol to form an ester.

3. The behaviour of the compound formed indicetes it to be glycol difuroete oe ethylene difuroate. 4. The physical and chemical properties of this compound, which had not previously been prepared, were determinea as far as possible. 
V.Furoyl Chloride:Reaction with Glycerol 


\section{A. Theoretical}

For the action of benzoyl chloride, an analogue of furoyl chloride, on polyhydric alcohols see the preceding aiscussion(this thesis IV,A, 16). Suffice it to say here that glycerine dibenzozte $\left(\mathrm{m} . \mathrm{p} .60^{\circ} \mathrm{C}.\right)$ and glycerine tribenzoate $\left(\mathrm{m} \cdot \mathrm{p} \cdot 70^{\circ}-76^{\circ} \mathrm{C}.\right)$ heve been prepered and identified from the reaction of benzoyl chloride on glycerine. 


\section{B. Objectives}

The objectives of this study are:

1. To demonstrate the similarity between the reaction of benzoyl chloride and that of furoyl chloride; 2.To demonstrate the action of furoyl chloride on the hydroxyl groups of glycerol;

3. To isolate and identify the product formed by the action of furoyl chloride on glycerol. 


\section{C.Experimental}

Experiment No.\# 1-Preparation of Furoyl Chloride

The furoyl chloride used in this experiment was prepared by the seme method as that used in the preceding experiments(this thesis II, C, IO).

Experiment No.\# 2-Preparation and Isolation of the Ester

A mixture consisting of $4 \mathrm{cc}$. of glycercl(from which all the water had been removed), $10 \mathrm{cc}$. of furoyl chloride and $50 \mathrm{cc}$. of $10 \%$ sodium hydroxide was placed in an eight inch test tube. The tube was stoppered and shaken vigorously until \& white resinous precipitate appeared.20 cc. of cold water were then added and the sheking continued for two minutes under cold water. The precipitate was separeted by filtration and washed with cold water and dilute scetic acid. The crystals were dissolved and recrystallized from hot dilute alcohol and dried on a porous plate.

Experiment No.\# 3-Identification of the Ester An examination of the product revealed the following:

a. Physical Appearance

The product was a white fluffy,crystalline compound possessing a pleasent odor. On ignition no residue 
renained, showing that the compound consisted essentially of carbon, hydrogen or oxygen and contained no metellic elements.

b. Solubility

The compound was soluble in ether, hot water and hot alcohol, but insoluble in cold water, cold alcohol, and dilute acods snd alkalies.

c.Physicel constents

(1) Melting point

The compound under examination melted at $98.5^{\circ} \mathrm{C} .($ uncorrected).

(2) Molecular weight

The molecular weight was determined according to the method outlined above(this thesis, III,C,1I). The values obtained were as follows:

Wt. tube-nn

Wt. tubets amp le---n-.-.-- $1980 \mathrm{gm}$

Wt. tube+sample tc amphor--- - .223lgm

Wt. sample-......-......-.0030 gm

Wt.c amphor..............025lgm

Temperatures

$$
\begin{array}{cc}
165.0^{\circ} & 162.0^{\circ} \\
165.0^{\circ} & 163.0^{\circ} \\
165.0^{\circ} & 162.5^{\circ} \\
\text { Average temp. }=163.75^{\circ}
\end{array}
$$$$
\text { Mol.wt. }=\frac{39.7 \times 1000 \times .003}{(176.4-163.75) .0251}
$$

Mol.Wt. $=375.1$ 
(Calculated Mol.Wt. $=374.09$ \%error $=25 \%$ )

(3) Saponification Ecuivalent The procedure outlined was like that outlined above (this thesis, III, C,13). The values obtained were:

$10 \mathrm{cc}$. alkali $=18.9 \mathrm{cc}$. ecid $/ .00937 \mathrm{~N}$ $.16891 \mathrm{~N}=$ Nomality of alkali

cc.N acid required for $40 \mathrm{cc}$. alkali= $40 \times .16891=6.7564$ cc.N acid required for excess alkeli= cc.N acid used by semple $(.2707 \mathrm{gm})=\frac{68.6 \times .08937}{=.6256}$

$$
\begin{aligned}
& \text { S.E. }=\frac{.2080 \times 1000}{.6256} \\
& \text { S.E. }=332.4
\end{aligned}
$$

(Celeulated S.E.336 $\%$ error $1.10 \%$

\section{d. Derivatives}

$5 \mathrm{cc}$. of the alkaline saponification mixture were distilled. The distillate was evaporated to dryness over a water bath and the residue extracted with a mixture of alcohol and ether. The solvent was evaporated, leaving a syrup. One drop of this syrup was treated with $0.5 \mathrm{gm}$ of potessium acid sulphate and placed in a test tube fitted with a delivery tube leading to a tube of distilled water. The sulphate mixbure was ignited until frothing ceased 
and the mixture was completely liquefied. The aqueous solution immediately acquired the odor characteristic of acrolein.of this solution a 2 cc. portion was treated with 5 cc. of fuchsine aldehyde reagent. An intial vivid violet coloretion aopeared and then turned to orange end to bluegreen after stending overnight followed by treatment with hydrochloric acid.This color change id characteristic of acrolein and serves to identify glfcerol as one of the original products of saponification. The remainder of the saponification mixture was acidified with dilute sulfuric acid and shaken with ether. The ether solution was separated and evaporcted after being dried with fused masnesium sulphate.A white crystalline solid, furoic acid resulted (m.p. $\left.128^{\circ} \mathrm{C}.\right)$. 


\section{Equations}

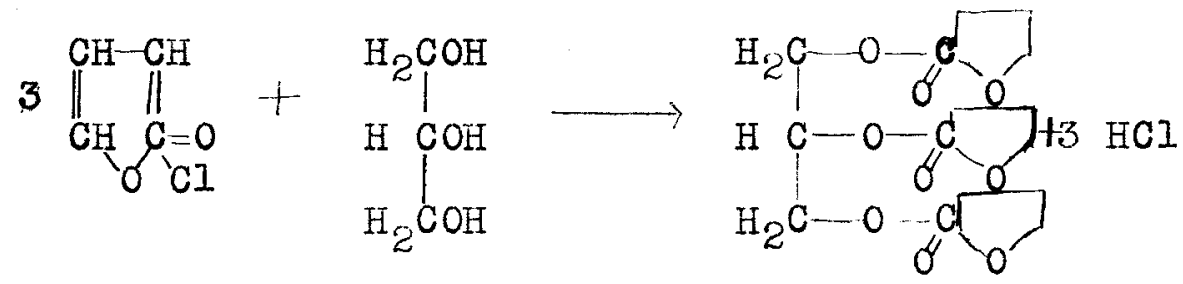<smiles>[R16][14C](=O)c1ccco1</smiles>

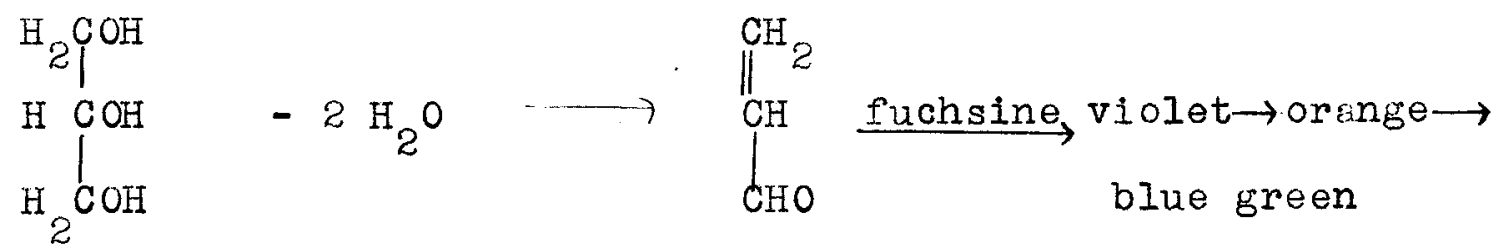




\section{E. Conclusions}

The findings of these experiments serve as the basis for the following conclusions:

1. Furoyl chloride reacts with glycerol in a manner analogous to that of benzoyl chloride;

2. Furoyl chloride reacts with all of the hydroxyl groups of glycerol to form an ester;

3. The product formed by the action of furoyl chloride upon glycerol has the properties which would identify it as glycerine trifurdate, not previously prepared;

4. The physical and chernical properties of the newly prepared compound were determined as far as possible. 
VI.General Summary 


\section{General Summary}

The findings of this series of investigations indicate that:

1. As far as the author was abie to determine, furfural does not react with chlorine to form the acid chloride as benzaldehyde.does.

2. Furoyl chloride reacts with the hydroxyl

groups of hyaroxy acids and of polyhydric alcohols to form esters. This is adaitional proof of the analogy between the activity of benzoyl chloride and that of furoyl chloride.

3. Difuroyltartrate, ethylene difuroate, and glycerine trifuroate have been prepared and their properties determined. 
Bibliography 


\section{Bibliography}

1. Dobereiner-Ann., 3 , 141 (1832).

2. The Furans, Quaker Oats Co., Technical Division, p.6, (1935):

3.Miner, Trickey and Brownlee-Chem. and Met.Eng.,27, 299, (1922).

4. Iies Bodart-Ann.,100,325, (1856).

5.Frankland and Ashton-J.Chem.Soc.,79,511, (1901).

6.Gelissen and Van Roon-Rec.trav.chim., 43 359, , (1924). 7.Gilman and Hewlett-Iowa State College J.Sci., , 27, (1929).

8.Hartmen and Dickey-Ind. and Eng. Shem.,24,151, (1932). 9. Richter's Organic Chemistry-D'Albe-I, 269. P.Blakiston's sons and Co.,1922.

10.Cross and Cohen-Proc.Chem.Soc.,24,15 (1908).

11. Darzens-Compt.rend., 1527314, (1911).

12.K1rner-J.Am.Chem.Soc., 50, 1955, (1928).

13.Willians-J.Chem.Soc.,109,2783, (1931).

14.Kaufler and Kunz-Ber., 42,385, (1909).

15.Barthe-Compt.rend., 145, 75, (1854).

16.Miner, Trickey and Brownlee-Chem. and Met.Eng.,27, 362 , (1922).

17.Adams and Vollweiler-Jam.Chem.Soc.,40,1732, (1918). 18.Gilman and Towne-Rec.trav.chim.,51,1054, (1932). 19.Gilman and Young-J.Am.Chem.Soc.,56,464, (1934). 
20.Gilman and Calloway-J.Am.Chem.Soc.,55,4197, (1933*. 21.Davis,U.S.1,834,686.Dec.1.,C.A.,26,994, (1933). 22. Baumann-Ber., 37, 2949,4756 (1904). 23. Smith and Young-J.Biol.Chem.,75, 289, (1927). 24.Baumann-Ber.,21, 2744, (1888). 25.Kamm, Qualitative Organic Analysis, John Wiley and Sons, H.Y., P.140.

26. Skraup-Ber.,22,R.668, (1889).

27. Diez-Z.f.Physiol.Chemie, XI, 472. 28.Muliken-Identification of Pure orgenic Compounds, I,169, John Wiley and Sons. 29.Mullikan-Identification of Pureorganic Compounds, I,63,John Wiley and Sons. 